\title{
Rapid eye movement sleep behavior disorder
}

\author{
Michael C. Chen ${ }^{1}$, Huan Yu ${ }^{2}$, Zhi-Li Huang ${ }^{3}$, and Jun Lu ${ }^{1}$ \\ ${ }^{1}$ Department of Neurology, Beth Israel Deaconess Medical Center and Harvard Medical School, \\ Boston, MA 02215, USA \\ 2Sleep and Wake Disorders Center and Department of Neurology, Huashan Hospital and Fudan \\ University, Shanghai 200040, China \\ ${ }^{3}$ Department of Pharmacology, Shanghai Medical College and Fudan University, Shanghai \\ 200032, China
}

\begin{abstract}
Rapid eye movement (REM) sleep behavior disorder (RBD) is a failure of the circuitry regulating motor atonia during REM sleep. In REM sleep, neurons of the sublaterodorsal tegmental nucleus (SLD) project to interneurons in the ventromedial medulla (VMM) and spinal cord that in turn inhibit spinal motoneurons. In RBD, degeneration of this circuitry disinhibits phasic motor commands originating from motor generators. The resulting behavior ranges from simple twitches or jerks to complex behavior. Simple behaviors in RBD may originate from cortical, brainstem and spinal cord motor generators, while complex behavior may originate from cortical motor generators, possibly related to dream content in REM sleep. While RBD can occur idiopathically, it is usually comorbid with or a precursor to a synucleinopathy such as Parkinson's disease (PD). RBD can precede the onset of PD by decades, suggesting a an underlying pathology that can progressively afflict REM atonia and midbrain dopaminergic centers. The relative recovery of motor function during REM sleep in some cases of PD with RBD emphasizes the complexity of motor pathway control during wakefulness and REM sleep.
\end{abstract}

\section{Introduction}

Failure of motor atonia control during rapid eye movement (REM) sleep results in a striking phenotype in which the normal quiescence of sleep is punctuated by movements ranging from simple behaviors, such as repetitive jerks, to complex behaviors, such as violent defensive thrashing in response to primal dream content. This disorder, REM sleep behavior disorder (RBD) [1], has a prevalence of $0.05 \%$ to $0.5 \%$ [2]. RBD can be idiopathic, but most cases of RBD either are comorbid with or precede, often by decades, the development of several neurodegenerative disorders, including Parkinson's disease (PD), multiple system atrophy (MSA), and dementia with Lewy-bodies (DLB) [2-7]. RBD is also comorbid with narcolepsy with cataplexy, although this mostly results in disinhibition of simple behaviors like twitches $[8,9]$. Although rare, RBD may shed light on the neural circuitry underlying REM sleep, motor control, and the development of neurodegenerative disorders.

\footnotetext{
(C) 2013 Elsevier Ltd. All rights reserved.

Correspondence to: Michael C. Chen; Jun Lu.
}

Publisher's Disclaimer: This is a PDF file of an unedited manuscript that has been accepted for publication. As a service to our customers we are providing this early version of the manuscript. The manuscript will undergo copyediting, typesetting, and review of the resulting proof before it is published in its final citable form. Please note that during the production process errors may be discovered which could affect the content, and all legal disclaimers that apply to the journal pertain. 


\section{REM sleep behavior disorder}

Like wakefulness, normal REM sleep features corticohippocampal activation, but unlike wakefulness, postural muscles have sustained, or tonic, atonia to prevent movement. Smaller muscles, including cranial muscles such as those regulating eye movements, show phasic activity bursts that emerge through the tonic atonia. This phasic activity can be concurrently seen in the cortex, thalamus, and the pons. In RBD, motor commands supercede the tonic atonia of REM sleep, resulting in motor behaviors. These motor commands can originate from primary and premotor cortices, with input from the basal ganglia, or from brainstem or spinal cord motor generators [10-12] (Figure 1a). In humans, these motor commands range from twitches to dream mentation-linked actions that mimic wakefulness. However, motor behavior in RBD can be jerky compared to wakefulness [13], and dream content can become skewed toward violent, defensive nightmares [14], perhaps as a result of the motor behaviors themselves [15].

The neural circuitry involved in RBD has not yet been identified. Researchers have proposed various brain regions that are responsible for maintaining atonia in REM sleep, forming an antagonistic system that prevents the expression of phasic muscle activity during REM sleep. During REM sleep atonia, motoneurons are inhibited by glycine-mediated inhibitory postsynaptic potentials [16]. Several possibilities exist for the source of this inhibitory signal. The first clue to the identity of these neurons came from Jouvet's pioneering work showing that electrolytic lesions in the sub-locus coeruleus (LC) in cats resulted in uninhibited movements during REM sleep, ranging from simple twitches to complex chasing behavior [17]. These findings were confirmed and extended by Morrison and colleagues in the 1980s [18]. The rat homolog of this structure, located ventral to the caudal laterodorsal tegmental nucleus (cLDT) and rostral to the LC, is the sublaterodorsal tegmental nucleus (SLD); recent work has identified this structure's critical role in REM sleep and atonia $[19,20]$. Neurons of the SLD send reticulospinal glutamatergic projections directly to the inhibitory interneurons in layer VII of the spinal cord [21]. We have proposed that during REM sleep, the SLD glutamatergically stimulates these glycinergic/GABAergic interneurons, which in turn antagonize the phasic excitatory inputs from motor cortex and brainstem to motor neurons (Figure 1b). Consistent with this formulation, loss of these SLD neurons, either via lesions of the SLD or by selective deletion of vesicular glutamate transporter 2 (vGLUT2) in a conditional knockout mouse, results in enacted motor behavior during REM sleep, including both simple and complex behaviors [20,21]. In humans, focal lesions due to stroke or inflammation in the mesopontine tegmentum, the putative location of the human homologue of the SLD, results in RBD [22] (Figure 1c).

SLD control of REM atonia may also be mediated by the ventromedial medulla (VMM). The VMM, particularly the area dorsal to the inferior olive (supraolivary medulla, SOM), also sends glutamatergic projections to inhibitory spinal interneurons, which may then in turn inhibit spinal motorneurons [21]; indeed the conditional knockout of VGLUT2, but not vesicular GABA transporter (VGAT), in the SOM results in a similar REM sleep atonia phenotype as VMM lesioned animals. Other glycinergic projections from the rostral ventromedial medulla (RVM) directly target spinal motoneurons [23], which combined with the incomplete loss of atonia with glutamate loss in VMM neurons [21], is suggestive of a direct inhibitory role for these projections [24]. During REM sleep, VMM lesioned animals express simple motor behaviors confined to the lower body and tail, during REM sleep. These animals do not show complex behaviors as in SLD lesions, but they do sporadically show some whole-body behaviors, like leaping, at the end of REM sleep. Thus, in addition to direct SLD glutamatergic projections to inhibitory spinal interneurons, the VMM, with input from the SLD and a complex distribution of both glutamatergic and GABA/ 
glycinergic projections, plays a unique role in suppressing the phasic activity of postural muscles during REM sleep (Figure 1b).

\section{Motor Phenotypes in RBD}

Patients with RBD can have simple and/or complex motor behaviors, often occurring in the same patient $[13,25]$. Simple motor behaviors appear myoclonic, jerky, and purposeless; complex motor behaviors often match the complexity and robustness of waking behavior, albeit with eyes closed [26]. Simple motor behaviors in RBD occur frequently, in almost all REM sleep periods, while complex behaviors are less common and vary from night to night. Lesions of the SLD in rodents produce both simple myoclonic twitches as well as complex behaviors such as locomotion and jumping [20]. As expected, RBD cases with complex behavior include patients with lesions of the SLD human homolog. Cases that only show simple behaviors, such as RBD in nacrolepsy with cataplexy and antidepressant induced RBD [27-29], may result from less severe SLD dysfunction, and thus a less severe loss of atonia, or from dysfunction in other REM atonia modulating circuits, including sites in the mesopontine junction [30].

The different classes of motor behavior in RBD may also depend on the origin of the motor input. Simple motor behaviors may arise from either cortex or brainstem motor pattern generators [31] and local circuits in the spinal cord itself, while complex motor behaviors arise from cortical primary and supplementary motor areas [32]. Complex motor behaviors during REM sleep in humans may be associated with the content of dreams, for example complex motor actions like smoking or the violent defensive behavior that can occur during a nightmare in which a patient is being attacked [33]. Primate premotor and primary motor cortex, which can directly project to spinal motoneurons rather than to spinal interneuron pattern generators [34], may allow uniquely complex fine motor skills to be expressed in humans with RBD. On the other hand, the phasic drive for simple twitches, for example jaw and tongue twitches arising from the motor nucleus branch of the trigeminal nerve (Mo5), are driven by glumatergic inputs from brainstem regions such as the parvocellular reticular nucleus (PCRt) [35] or other pattern generators. These twitches are reminiscent of neonatal active-sleep twitches, which can arise from brainstem and spinal cord generators [36]. Indeed REM sleep twitching is preserved in cats in which transections prevent corticospinal input [37]. Other phasic events, including eye movements or autonomic fluctuations, may be unperturbed in RBD, suggesting that RBD results in a disturbance in the circuitry inhibiting phasic events, rather than a disturbance in the circuitry generating phasic events.

The quantity and structure of REM sleep itself is mostly preserved in RBD [5]; the number, density, and onset latency of REM sleep periods are normal in most RBD cases, although the content of dreams in REM sleep may become more primal or violent [14]. The interaction of REM-on and REM-off neurons regulates the transitions into and the maintenance of REM sleep. The REM-on GABAergic neurons in the caudal laterodorsal tegmentum (cLDT) and SLD interact with REM-off neurons in the ventrolateral periaqueductal gray (vlPAG) and lateral pontine tegmentum (LPT), which also receive inputs from the ventrolateral preoptic nucleus (VLPO), melanin-concentrating hormone neurons of the hypothalamus, as well as the brainstem pedunculopontine tegmentum, LC, and dorsal raphe nucleus. Recent work has challenged the model of reciprocal interactions between the SLD and vlPAG/LPT in generating REM sleep [38], specifically the GABAergic projections of the SLD to vlPAG/LPT, although these different findings may result from key differences in the definition of the SLD and the method of REM sleep deprivation. The output of the REM-on neurons includes glutamatergic projections to the forebrain via the parabrachial/precoeruleus nuclei, as well as the aforementioned VMM and spinal cord projections that regulate atonia. Lesions confined to the SLD in rats do not alter 
REM sleep time [20,21], but lesions or VGLUT2 knockdown in both the SLD and REM sleep circuitry in the cLDT reduce REM sleep time and REM sleep period consolidation. The lack of gross changes to REM sleep in most RBD cases suggests a specific pathology to REM atonia circuitry, rather than a dysfunction in REM sleep circuitry.

\section{RBD and Neurodegenerative Disorders}

The dissection of RBD behaviors and REM atonia circuitry may also reveal aspects of the pathology of RBD in the context of neurodegenerative disorders. In PD, basal ganglia dysfunction impairs motor function (Figure 1a). The proposed pathology of RBD in PD is compatible with the alpha-synuclein deposition and Lewy bodies that are reported in the subcoeruleus (SC) region in RBD with or without PD [39,40] (Figure 2b). The dopamine loss that characterizes PD does not contribute to the RBD, as dopaminergic agonists have limited effect on RBD symptoms [41]. Some PD patients never display RBD symptoms [5], suggesting that neuronal dysfunction can afflict the substantia nigra pars compacta ( $\mathrm{SNc}$ ) and SLD together in PD with RBD or separately in PD without RBD or idiopathic RBD. However, RBD occurs in 40-60\% of PD patients [5], and $80 \%$ or more of patients with idiopathic RBD eventually develop PD or DLB [3-7]. Likewise, almost all patients with MSA, a synucleinopathy, have RBD, whereas the presence of RBD in degenerative diseases such as supranuclear palsy [42] and Alzheimer's disease [43] is extremely rare. RBD with PD tends to occur in males [4,44], in agreement with the prevalence of PD in males [45]; research on the possibility of gender-related effects on synucleinopathies underlying RBD pathology is needed to clarify this association. Clearly, there is a strong association between the pathology of synucleinopathies and the pathology of RBD, and while some cases of idiopathic RBD may be an isolated degeneration of this REM atonia complex, the majority of idiopathic RBD cases likely have an underlying synucleinopathy that manifests more fully in time.

The temporal association of RBD and PD may help disentangle the motor pathways in simple and complex RBD. In PD with RBD, as well as MSA with RBD, movement symptoms and dysarthria present during wakefulness improve during REM sleep, although this improved motor behavior is not as refined as normal behavior [46,47]. This has lead to the hypothesis that during PD with RBD, motor commands from the cortex, particularly the primary and supplementary motor cortex, bypass both basal ganglia modulationdysfunctional due to the PD—and SLD/SC complex inhibition-dysfunctional due to RBD —enabling movement (Figure 2b) [48]. Key differences in basal ganglia firing rates and patterns during REM sleep compared to wake $[49,50]$ may help explain why cortical motor commands are not as disrupted by the basal ganglia during REM sleep as they are during wakefulness. Another possibility is that differences in basal ganglia projection patterns to premotor and primary motor regions [51] resolve premotor dysfunction during REM sleep (Figure 2c). This premotor dysfunction impairs movement initiation during wakefulness [52], but during REM sleep, primary motor cortex may trigger movement without deleterious influence from premotor regions.

\section{Conclusion}

We propose a spectrum of RBD based on the involvement of the putative circuitry of REM sleep atonia and the complexity of symptoms in RBD. In RBD with simple behaviors, VMM lesions, partial SLD lesions, or pharmacological changes (eg. selective serotonin reuptake inhibitors [53]), disinhibit simple phasic motor behavior arising from either cortex or brainstem and spinal cord generators. In RBD with more complex behaviors, more extensive lesions of the SLD disinhibit phasic motor activity of both simple and complex behaviors during REM sleep. This delineation predicts a spectrum of pathologies underlying other 
behaviors in RBD, for example the varying complexity of vocalizations during REM sleep. In RBD with simple behaviors, innate vocalizations like screaming or groaning, originating from the anterior cingulate cortex, periaqueductal gray (PAG), or reticular pattern generators, are disinhibited during REM sleep. In RBD with complex behaviors, extensive REM atonia circuit lesions disinhibit complex vocalizations, like speech, originating from primary motor cortex, which integrates other language network inputs. Disentangling the neural pathways involved in this spectrum of behaviors in RBD will shed light on not only REM atonia circuitry but also the unique relation between RBD and neurodegenerative disorders, the neural basis of motor behavior, and why drugs like clonazepam are effective at treating the complex behaviors of RBD [54]. Clinical studies in humans of motor behaviors across the wake-sleep-REM spectrum, in conjunction with functional circuit mapping in animal models, are both needed to understand RBD.

\section{Acknowledgments}

M.C.C. is supported by NIH HL007901. J.L. is supported by NIH NS 062727 and NS 061841.

\section{References}

1**. Schenck CH, Bundlie SR, Ettinger MG, Mahowald MW. Chronic behavioral disorders of human REM sleep: a new category of parasomnia. Sleep. 1986; 9:293-308. This is the first clinical report of RBD in humans, which also suggested a pontine pathology and an association with neurodegenerative disorders. [PubMed: 3505730]

2. Boeve BF. REM sleep behavior disorder: Updated review of the core features, the REM sleep behavior disorder-neurodegenerative disease association, evolving concepts, controversies, and future directions. Ann N Y Acad Sci. 2010; 1184:15-54. [PubMed: 20146689]

3. Boeve BF, Silber MH, Parisi JE, Dickson DW, Ferman TJ, Benarroch EE, Schmeichel AM, Smith GE, Petersen RC, Ahlskog JE, et al. Synucleinopathy pathology and REM sleep behavior disorder plus dementia or parkinsonism. Neurology. 2003; 61:40-45. [PubMed: 12847154]

4. Postuma RB, Gagnon JF, Vendette M, Fantini ML, Massicotte-Marquez J, Montplaisir J. Quantifying the risk of neurodegenerative disease in idiopathic REM sleep behavior disorder. Neurology. 2009; 72:1296-1300. [PubMed: 19109537]

5. Iranzo A, Santamaria J, Tolosa E. The clinical and pathophysiological relevance of REM sleep behavior disorder in neurodegenerative diseases. Sleep Medicine Reviews. 2009; 13:385-401. [PubMed: 19362028]

6. Claassen DO, Josephs KA, Ahlskog JE, Silber MH, Tippmann-Peikert M, Boeve BF. REM sleep behavior disorder preceding other aspects of synucleinopathies by up to half a century(e-Pub ahead of print)(CME). Neurology. 2010; 75:494-499. [PubMed: 20668263]

$7 * *$. Schenck CH, Bundlie SR, Mahowald MW. Delayed emergence of a parkinsonian disorder in 38\% of 29 older men initially diagnosed with idiopathic rapid eye movement sleep behaviour disorder. Neurology. 1996; 46:388-393. This important report showed that many patients with idiopathic RBD develop Parkinson's disease in time, providing an important link between RBD and neurodegenerative disorders. [PubMed: 8614500]

8. Dauvilliers Y, Jennum P, Plazzi G. REM sleep behavior disorder and REM sleep without atonia in narcolepsy. Sleep Med. 201210.1016/j.sleep.2012.10.006

9. Franceschini C, Ferri R, Pizza F, Ricotta L, Vandi S, Detto S, Poli F, Pruneti C, Mazzetti M, Cipolli $\mathrm{C}$, et al. Motor events during REM sleep in patients with narcolepsy-cataplexy: a videopolysomnographic pilot study. Sleep Med. 2011; 12 (Suppl 2):S59-63. [PubMed: 22136902]

10. Grillner S, Zangger P. On the central generation of locomotion in the low spinal cat. Exp Brain Res. 1979; 34:241-261. [PubMed: 421750]

11. Noga BR, Kettler J, Jordan LM. Locomotion produced in mesencephalic cats by injections of putative transmitter substances and antagonists into the medial reticular formation and the pontomedullary locomotor strip. J Neurosci. 1988; 8:2074-2086. [PubMed: 2898514] 
12. Blumberg MS, Lucas DE. Dual mechanisms of twitching during sleep in neonatal rats. Behav Neurosci. 1994; 108:1196-1202. [PubMed: 7893412]

13. Manni R, Terzaghi M, Glorioso M. Motor-behavioral episodes in REM sleep behavior disorder and phasic events during REM sleep. Sleep. 2009; 32:241-245. [PubMed: 19238811]

14. Olson EJ, Boeve BF, Silber MH. Rapid eye movement sleep behaviour disorder: demographic, clinical and laboratory findings in 93 cases. Brain. 2000; 123:331-339. [PubMed: 10648440]

15. Fantini ML, Corona A, Clerici S, Ferini-Strambi L. Aggressive dream content without daytime aggressiveness in REM sleep behavior disorder. Neurology. 2005; 65:1010-1015. [PubMed: 16217051]

16. Chase MH, Soja PJ, Morales FR. Evidence that glycine mediates the postsynaptic potentials that inhibit lumbar motoneurons during the atonia of active sleep. J Neurosci. 1989; 9:743-751. [PubMed: 2926479]

17**. Jouvet M, Delorme F. Locus coeruleus et sommeil paradoxal. CR Soc Biol (Paris). 1965 [no volume]. This seminal work by Jouvet and Delorme revealed that lesions of the LC in the cat eventually led to hallucinatory behavior with sleep and wake-like characteristics, suggesting a critical role for the LC and surrounding area for generating RBD-like states. The descriptions also hint at the complexity of and propensity for violence in the behavioral repertoire of this RBD-like phenotype.

18. Morrison AR, Mann GL, Hendricks JC. The relationship of excessive exploratory behavior in wakefulness to paradoxical sleep without atonia. Sleep. 1981; 4:247-257. [PubMed: 7302456]

19*. Boissard R, Gervasoni D, Schmidt MH, Barbagli B, Fort P, Luppi P-H. The rat ponto-medullary network responsible for paradoxical sleep onset and maintenance: a combined microinjection and functional neuroanatomical study. European Journal of Neuroscience. 2002; 16:1959-1973. This paper identified the SLD, and specifically glutamatergic signaling of these neurons, as a critical region for the control of REM sleep. [PubMed: 12453060]

20*. Lu J, Sherman D, Devor M, Saper CB. A putative flip-flop switch for control of REM sleep. Nature. 2006; 441:589-594. This paper clarifies the brainstem control loci of REM sleep and atonia, including the spinal projections of the rat SLD. [PubMed: 16688184]

21. Vetrivelan R, Fuller PM, Tong Q, Lu J. Medullary Circuitry Regulating Rapid Eye Movement Sleep and Motor Atonia. J Neurosci. 2009; 29:9361-9369. [PubMed: 19625526]

22. Iranzo A, Aparicio J. A lesson from anatomy: focal brain lesions causing REM sleep behavior disorder. Sleep Med. 2009; 10:9-12. [PubMed: 18606568]

23. Hossaini M, Goos JAC, Kohli SK, Holstege JC. Distribution of Glycine/GABA Neurons in the Ventromedial Medulla with Descending Spinal Projections and Evidence for an Ascending Glycine/GABA Projection [Internet]. PLoS One. 2012:7.

24. Morales FR, Sampogna S, Rampon C, Luppi PH, Chase MH. Brainstem glycinergic neurons and their activation during active (rapid eye movement) sleep in the cat. Neuroscience. 2006; 142:3747. [PubMed: 16891059]

25. Frauscher B, Gschliesser V, Brandauer E, Ulmer H, Poewe W, Högl B. The relation between abnormal behaviors and REM sleep microstructure in patients with REM sleep behavior disorder. Sleep Med. 2009; 10:174-181. [PubMed: 18359665]

26. Oudiette D, De Cock VC, Lavault S, Leu S, Vidailhet M, Arnulf I. Nonviolent elaborate behaviors may also occur in REM sleep behavior disorder. Neurology. 2009; 72:551-557. [PubMed: 19204265]

27. Billiard M. REM sleep behavior disorder and narcolepsy. CNS Neurol Disord Drug Targets. 2009; 8:264-270. [PubMed: 19689308]

28. Dauvilliers Y, Arnulf I, Mignot E. Narcolepsy with cataplexy. Lancet. 2007; 369:499-511. [PubMed: 17292770]

29. Winkelman JW, James L. Serotonergic antidepressants are associated with REM sleep without atonia. Sleep. 2004; 27:317-321. [PubMed: 15124729]

30. Lai Y-Y, Hsieh K-C, Nguyen D, Peever J, Siegel JM. Neurotoxic lesions at the ventral mesopontine junction change sleep time and muscle activity during sleep: An animal model of motor disorders in sleep. Neuroscience. 2008; 154:431-443. [PubMed: 18487021] 
31. Tassinari CA, Rubboli G, Gardella E, Cantalupo G, Calandra-Buonaura G, Vedovello M, Alessandria M, Gandini G, Cinotti S, Zamponi N, et al. Central pattern generators for a common semiology in fronto-limbic seizures and in parasomnias. A neuroethologic approach. Neurol Sci. 2005; 26 (Suppl 3):s225-232. [PubMed: 16331401]

32. Dauvilliers Y, Yves D, Boudousq V, Vincent B, Lopez R, Regis L, Gabelle A, Audrey G, De Cock VC, Valérie CDC, et al. Increased perfusion in supplementary motor area during a REM sleep behaviour episode. Sleep Med. 2011; 12:531-532. [PubMed: 21489868]

33. Borek LL, Kohn R, Friedman JH. Phenomenology of dreams in Parkinson's disease. Mov Disord. 2007; 22:198-202. [PubMed: 17133561]

34. Rathelot J-A, Strick PL. Subdivisions of primary motor cortex based on cortico-motoneuronal cells. Proc Natl Acad Sci U S A. 2009; 106:918-923. [PubMed: 19139417]

35. Anaclet C, Pedersen NP, Fuller PM, Lu J. Brainstem circuitry regulating phasic activation of trigeminal motoneurons during REM sleep. PLoS ONE. 2010; 5:e8788. [PubMed: 20098748]

36. Kreider JC, Blumberg MS. Mesopontine contribution to the expression of active "twitch" sleep in decerebrate week-old rats. Brain Res. 2000; 872:149-159. [PubMed: 10924687]

37. Villablanca J. Behavioral and polygraphic study of "sleep" and "wakefulness" in chronic decerebrate cats. Electroencephalogr Clin Neurophysiol. 1966; 21:562-577. [PubMed: 4162886]

38. Sapin E, Lapray D, Bérod A, Goutagny R, Léger L, Ravassard P, Clément O, Hanriot L, Fort P, Luppi P-H. Localization of the Brainstem GABAergic Neurons Controlling Paradoxical (REM) Sleep [Internet]. PLoS ONE. 2009:4.

39. Boeve BF, Silber MH, Ferman TJ, Lucas JA, Parisi JE. Association of REM sleep behavior disorder and neurodegenerative disease may reflect an underlying synucleinopathy. Mov Disord. 2001; 16:622-630. [PubMed: 11481685]

40. Uchiyama M, Isse K, Tanaka K, Yokota N, Hamamoto M, Aida S, Ito Y, Yoshimura M, Okawa M. Incidental Lewy body disease in a patient with REM sleep behavior disorder. Neurology. 1995; 45:709-712. [PubMed: 7723959]

41. Kumru H, Iranzo A, Carrasco E, Valldeoriola F, Marti MJ, Santamaria J, Tolosa E. Lack of effects of pramipexole on REM sleep behavior disorder in Parkinson disease. Sleep. 2008; 31:1418-1421. [PubMed: 18853939]

42. Arnulf I, Merino-Andreu M, Bloch F, Konofal E, Vidailhet M, Cochen V, Derenne J-P, Agid Y. REM sleep behavior disorder and REM sleep without atonia in patients with progressive supranuclear palsy. Sleep. 2005; 28:349-354. [PubMed: 16173657]

43. Gagnon J-F, Petit D, Fantini ML, Rompré S, Gauthier S, Panisset M, Robillard A, Montplaisir J. REM sleep behavior disorder and REM sleep without atonia in probable Alzheimer disease. Sleep. 2006; 29:1321-1325. [PubMed: 17068986]

44. Iranzo A, Molinuevo JL, Santamaría J, Serradell M, Martí MJ, Valldeoriola F, Tolosa E. Rapideye-movement sleep behaviour disorder as an early marker for a neurodegenerative disorder: a descriptive study. Lancet Neurol. 2006; 5:572-577. [PubMed: 16781987]

45. De Lau LML, Giesbergen PCLM, De Rijk MC, Hofman A, Koudstaal PJ, Breteler MMB. Incidence of parkinsonism and Parkinson disease in a general population: the Rotterdam Study. Neurology. 2004; 63:1240-1244. [PubMed: 15477545]

46*. De Cock VC, Vidailhet M, Leu S, Texeira A, Apartis E, Elbaz A, Roze E, Willer JC, Derenne JP, Agid Y, et al. Restoration of normal motor control in Parkinson's disease during REM sleep. Brain. 2007; 130:450-456. This paper describes an improvement of PD motor symptoms during REM sleep, suggesting several possible pathways by which motor control is re-established despite underlying PD circuit pathologies. [PubMed: 17235126]

47. Cock VCD, Debs R, Oudiette D, Leu S, Radji F, Tiberge M, Yu H, Bayard S, Roze E, Vidailhet $\mathrm{M}$, et al. The improvement of movement and speech during rapid eye movement sleep behaviour disorder in multiple system atrophy. Brain. 2011; 134:856-862. [PubMed: 21310729]

48. Cochen De Cock V. Recent data on rapid eye movement sleep behavior disorder in patients with Parkinson's disease: Analysis of behaviors, movements and periodic leg movements [Internet]. Sleep Medicine. [date unknown]. 10.1016/j.sleep.2012.07.005 
49. Mahon S, Vautrelle N, Pezard L, Slaght SJ, Deniau J-M, Chouvet G, Charpier S. Distinct patterns of striatal medium spiny neuron activity during the natural sleep-wake cycle. J Neurosci. 2006; 26:12587-12595. [PubMed: 17135420]

50. Urbain N, Gervasoni D, Soulière F, Lobo L, Rentéro N, Windels F, Astier B, Savasta M, Fort P, Renaud B, et al. Unrelated course of subthalamic nucleus and globus pallidus neuronal activities across vigilance states in the rat. European Journal of Neuroscience. 2000; 12:3361-3374. [PubMed: 10998119]

51. Middleton FA, Strick PL. Basal-ganglia "Projections" to the Prefrontal Cortex of the Primate. Cereb Cortex. 2002; 12:926-935. [PubMed: 12183392]

52. Jahanshahi M, Jenkins IH, Brown RG, Marsden CD, Passingham RE, Brooks DJ. Self-initiated versus externally triggered movements. I. An investigation using measurement of regional cerebral blood flow with PET and movement-related potentials in normal and Parkinson's disease subjects. Brain. 1995; 118 ( Pt 4):913-933. [PubMed: 7655888]

53. Schenck CH, Mahowald MW, Kim SW, O'Connor KA, Hurwitz TD. Prominent eye movements during NREM sleep and REM sleep behavior disorder associated with fluoxetine treatment of depression and obsessive-compulsive disorder. Sleep. 1992; 15:226-235. [PubMed: 1621023]

54. Aurora RN, Zak RS, Maganti RK, Auerbach SH, Casey KR, Chowdhuri S, Karippot A, Ramar K, Kristo DA, Morgenthaler TI. Best Practice Guide for the Treatment of REM Sleep Behavior Disorder (RBD). J Clin Sleep Med. 2010; 6:85-95. [PubMed: 20191945] 


\section{Highlights}

- During rapid eye movement (REM) sleep, phasic motor activity is inhibited by a REM atonia circuit

- In REM sleep behavior disorder (RBD), inhibition is lost due to lesion of this REM atonia circuit

- In RBD, multiple putative motor generators drive simple or complex motor behaviors in REM sleep

- RBD can occur with or before a neurodegenerative disorder like Parkinson's disease

- In Parkinson's disease with RBD, movements may improve in REM sleep 
A

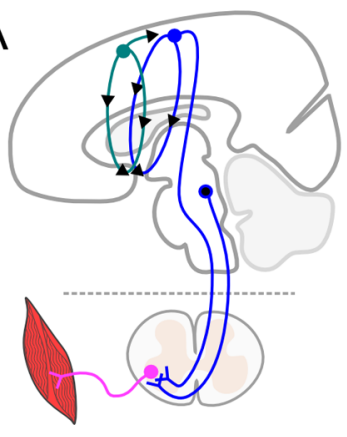

B

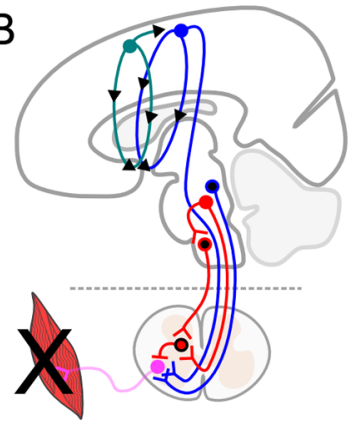

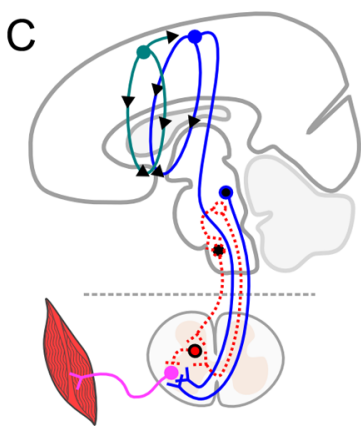

- SLD

- VMM

- SpIN

- SpMo

$Q \mathrm{BG}$

- BrMo

- $P M C$

- PreMo

$\prec$ Exc

$\dashv$ Inhib

Figure 1.

A simplified model of the interaction of motor function and REM atonia in humans. During wake (A), motor commands from primary (PMC) and premotor cortices (PreMo), with modulatory basal ganglia (BG) input, as well as brainstem motor pattern generators (BrMo), project to spinal motoneurons (SpMO) to drive motor behavior. During REM sleep (B), the SLD projections directly to inhibitory spinal interneurons (SpIN), as well as through the ventromedial medulla, inhibit SpMO and enforce atonia. In RBD (C), degeneration of the SLD and/or VMM releases this inhibition, resulting inappropriate motor activity during REM sleep. Note that in most non-primates, corticospinal projections target spinal pattern generators, rather than spinal motoneurons directly. 

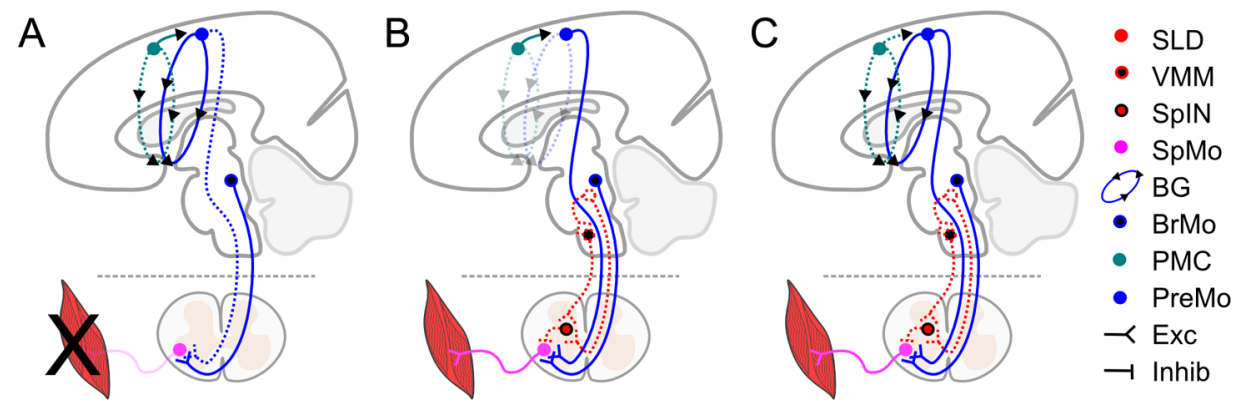

Figure 2.

A simplified model of the interaction of motor function in Parkinson's Disease (PD) and REM atonia. During wake in PD (A), dysfunctional BG input to premotor (PreMo) and primary motor cortex (PMC) impairs motor function. During RBD in PD, lesions to the SLD and/or VMM result in disinhibition of descending motor commands, resulting in motor behavior that in some aspects is improved over waking behavior. This may be due to PreMo and PMC bypass of dysfunctional BG modulation during REM sleep (B), or a specific reduction in dysfunctional PreMo influence on PMC motor commands due to different putative topographies of BG loops with PreMo and PMC (C). 